\title{
Outcome of Burkholderia (Pseudomonas) cepacia colonisation in children with cystic fibrosis following a hospital outbreak
}

\author{
Margo L Whiteford, Jane D Wilkinson, John H McColl, Fiona M Conlon, \\ Joanne R Michie, T John Evans, James Y Paton
}

\begin{abstract}
Background - While there are reports on the outcome in adults and teenagers with cystic fibrosis of colonisation with Burkholderia (Pseudomonas) cepacia, there is little information in children.

Methods - In December 1991 only one of 115 children with cystic fibrosis attending a paediatric centre was colonised with $B$ cepacia. Over the next 12 months there was a rapid increase with $23(20 \%)$ becoming colonised; eighteen ( $79 \%$ ) of these became colonised in hospital at a time that overlapped with the admission of a $B$ cepacia positive child. Three different bacteriocin types were isolated, with one type (S22/PO) being present in 17 (74\%) patients. The outcome for children who became colonised with $B$ cepacia was compared with that in 33 children who continued to be colonised with Pseudomonas aeruginosa alone.
\end{abstract}

Results - Children colonised with $B$ cepacia were older and more poorly nourished than those colonised with $P$ aeruginosa, but did not have poorer pulmonary function. After colonisation, the forced expiratory volume in one second $\left(F E V_{1}\right)$ deteriorated between consecutive annual tests, with the average deterioration being greater in those with higher initial levels. Five children with $B$ cepacia died from respiratory failure although none showed a fulminant deterioration. Introduction of segregation measures within hospital led to a dramatic decrease in the number of newly colonised patients.

Conclusions - This study provides further evidence for person-to-person spread of $B$ cepacia and confirms the effectiveness of simple isolation measures in interrupting spread. Colonisation with $B$ cepacia and $P$ aeruginosa in children is associated with a more rapid decline in lung function and a significantly increased mortality compared with cases colonised with $P$ aeruginosa alone.

(Thorax 1995;50:1194-1198)

Keywords: cystic fibrosis, children, Burkholderia (Pseudomonas) cepacia, lung function, cross infection.

In the early 1980 s cystic fibrosis centres in North America noted the emergence of Pseudomonas cepacia (Burkholderia cepacia) as an im- portant pathogen in patients with cystic fibrosis. Subsequent reports have described the outcome of patients with cystic fibrosis following colonisation with $B$ cepacia. ${ }^{1-6}$

Early studies suggested that $B$ cepacia may be acquired nosocomially, ${ }^{26}$ but more recent evidence has tended to confirm that $B$ cepacia may be transmitted from patient to patient. ${ }^{7}$ Patients colonised with $B$ cepacia also contaminate the immediate environment with a possible increase in the risks of indirect acquisition. ${ }^{8}$ However, there is still debate as to whether acquisition occurs mainly via direct person to person spread ${ }^{7-11}$ or from environmental sources within or outside the hospital. Notwithstanding, concerns about nosocomial spread have led many centres to segregate patients colonised with $B$ cepacia. ${ }^{5910}$

Reports on the outcome after $B$ cepacia colonisation have related predominantly to adults and adolescents with cystic fibrosis. We report the outcome of a hospital outbreak of $B$ cepacia in children with cystic fibrosis already colonised with $P$ aeruginosa attending a paediatric cystic fibrosis centre. Apart from providing further evidence of person to person spread, this outbreak allowed the outcome in the children who became colonised with $B$ cepacia in addition to $P$ aeruginosa to be compared with those remaining colonised with $P$ aeruginosa only.

\section{Methods}

PATIENTS

In 1992115 children of mean age $7 \cdot 6$ years (range $0 \cdot 6-15 \cdot 8$ ) attended the Cystic Fibrosis Unit at the Royal Hospital for Sick Children, Glasgow. Children with cystic fibrosis needing inpatient care were admitted to one ward where they had complete freedom to play together and socialise. Older children with cystic fibrosis attended the hospital school together.

\section{B CEPACIA OUTBREAK AND SUBSEQUENT} SEGREGATION POLICIES

At that time and for 18 months previously 56 children of mean age 8.9 years (range $2 \cdot 2-15 \cdot 8$ ) colonised with $P$ aeruginosa had had their chest physiotherapy separately from children in whom $P$ aeruginosa had not been isolated. Those with $P$ aeruginosa (other than infants and toddlers) attended the physiotherapy department twice daily; in those without $P$ aeruginosa physiotherapy was performed on their beds in the ward. Each child had an individual 


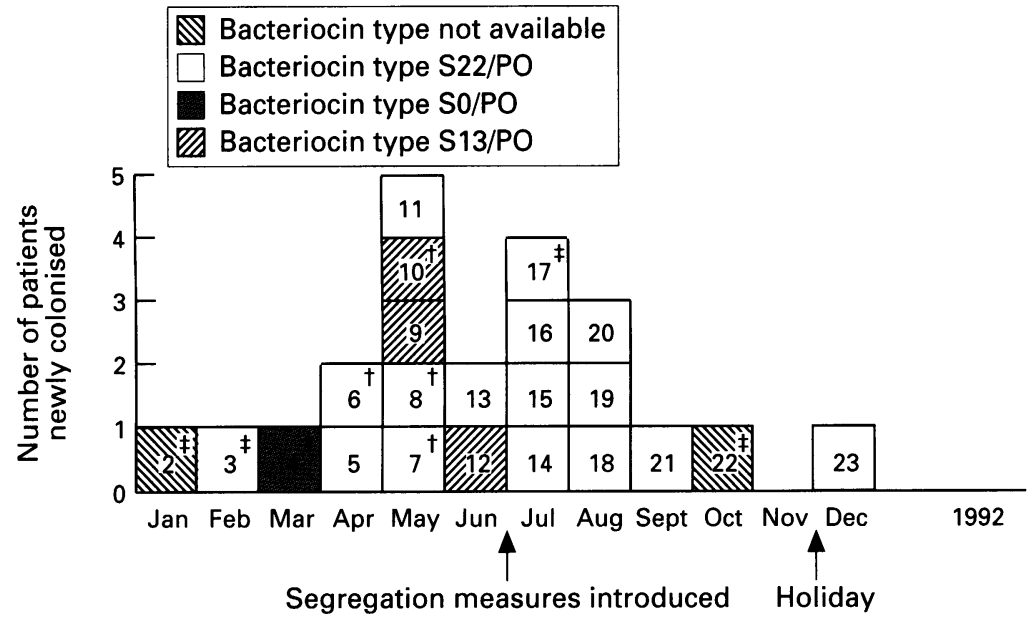

Consecutive cases of $B$ cepacia colonisation during the period of the study indicating periods of overlapping contact in hospital and bacteriocin types isolated. + Deceased; $\ddagger$ no inpatient contact with $B$ cepacia colonised patients.

peak flow meter and nebuliser for use throughout the admission.

From January to December 1992 there was a rapid increase in the number of children colonised with $B$ cepacia (figure) which occurred exclusively in children already colonised with $P$ aeruginosa. The nature and rapidity of the increase strongly suggested spread from child to child. Accordingly, in June 1992 (figure) segregation measures were introduced and thereafter children known to be colonised with $B$ cepacia were admitted to a separate ward. While all children with cystic fibrosis continued to attend a single outpatient clinic, those with $B$ cepacia were moved to a different waiting area and given appointment times at the end of the clinic. At the introduction of these measures a letter was sent to all parents of children attending the centre explaining the reasons for segregation and suggesting that it would be sensible for children with $B$ cepacia to avoid close physical contact with other children with cystic fibrosis outside hospital.

\section{MICROBIOLOGY}

Specimens for bacterial culture were either sputum samples or cough swabs in those unable to produce sputum.

Before the $B$ cepacia outbreak the microbiology laboratory had been routinely culturing and isolating $B$ cepacia for a number of years. During this period only three children with cystic fibrosis had ever been found to be colonised. At the time of the outbreak no changes had occurred in the handling of specimens or methods of culture.

All specimens were cultured fresh for $B \mathrm{ce}$ pacia. Specimens were plated on McConkey agar (Becton Dickinson, Cumbernauld, UK), $B$ cepacia selective media (Mast Diagnostics, UK) and blood agar plates (Oxoid Ltd, Oxford, $\mathrm{UK}$ ) and incubated at $37^{\circ} \mathrm{C}$ in $5 \% \mathrm{CO}_{2}$. After 24 hours incubation all plates were examined. Normal flora was recorded as "light", "moderate", or "heavy". Presumptive pathogenic organisms were identified by colony morphology and oxidase tests, plated onto blood agar purity plates, and incubated for a further 24 hours at $37^{\circ} \mathrm{C}$ in $5 \% \mathrm{CO}_{2}$. Diagnostic sensitivity agar plates (Becton Dickinson) and antibiotic impregnated discs (Oxoid Ltd) were used in a modified Stokes method for antibiotic sensitivity testing. Antibiotics tested included tobramycin $(10 \mu \mathrm{g})$, ceftazidime $(30 \mu \mathrm{g})$, aztreonam $(30 \mu \mathrm{g})$, ciprofloxacin $(1 \mu \mathrm{g})$, colistin sulphate $(10 \mu \mathrm{g})$, and azlocillin $(75 \mu \mathrm{g}) . B$ cepacia isolates were identified by $20 \mathrm{NE}$ API strips (Bio Merieux).

Bacteriocin typing of all $B$ cepacia organisms was performed by standard methods. ${ }^{12}$

COMPARISON OF CHILDREN COLONISED WITH $B$ CEPACIA AND THOSE COLONISED WITH $P$ AERUGINOSA

The group of children colonised with $P$ aeruginosa who became colonised with $B$ cepacia ("B cepacia group") was compared with the remaining children with $P$ aeruginosa who did not become colonised with $B$ cepacia ("P aeruginosa group") using data from approximately annual assessments of nutrition (height and weight centiles), respiratory status (peak expiratory flow rate (PEFR), forced expiratory volume in one second $\left(\mathrm{FEV}_{1}\right)$, residual volume to total lung capacity ratio (RV/TLC)), and Swachman score. ${ }^{13}$

For the $B$ cepacia group the results of two consecutive annual reviews were chosen corresponding as closely as possible to a period six months before and six months after colonisation with $B$ cepacia (average period between results 15.5 months; all data from September 1988 to September 1993). In the $P$ aeruginosa group we also used results of reviews approximately 12 months apart (average period between results 18.0 months; results obtained between March 1990 and September 1993).

\section{DATA ANALYSIS}

The data from children colonised with $B$ cepacia and those colonised with $P$ aeruginosa were compared using either $\chi^{2}$ tests of association or Fisher's exact test (as appropriate) for the categorical variables, and either two sample $t$ intervals or the non-parametric equivalent for the continuous variables. Group comparisons were undertaken because appropriate matching of cases from the two groups could not be achieved for the baseline parameters of age, sex, pulmonary function, and nutritional status. Analysis of covariance (ANCOVA) was used to examine possible effects of the initial status of the patient on the change in each pulmonary function test result. The recorded deterioration in each measurement was regressed on its initial value, separately for each of the two groups of patients, and a confidence interval for each slope parameter was derived to determine whether the initial value had an influence on deterioration. A model with parallel regression lines was next tested within the general model provided by wholly distinct regression in the two groups. Finally, a model with coincident regression lines, corresponding to the hypothesis of no group effect, was tested within the model with parallel lines (if appropriate). 


\section{Results}

TRANSMISSION OF B CEPACLA

The increase in children colonised with $B \mathrm{ce}$ pacia throughout 1992 is shown in the figure. Of the three children who had $B$ cepacia cultured between 1986 and 1992, only one had the organism present consistently at the start of the outbreak.

During January 1992 one child (subject 2, a two year old with mild disease and no hospital admissions from diagnosis at five weeks of age) had $B$ cepacia isolated from the sputum. As $B$ cepacia quickly cleared from the sputum and has not been isolated again, bacteriocin typing of this strain was not available. A second child (subject 3) with a respiratory exacerbation in January 1992 had a sputum sample on admission which grew three different strains of $P$ aeruginosa. B cepacia was isolated from a second sputum sample three days before discharge in February 1992. Thereafter the number of children with $B$ cepacia increased (figure) so that, by December 1992, 23 (20\%) were colonised.

In the $B$ cepacia group of 23 patients 19 had more than 10 separate isolates of the organism. Of these, 17 showed persistent colonisation and two intermittent colonisation. Four of the $B$ cepacia group had fewer than 10 isolates, and bacteriocin typing on these showed three to be S22/PO; typing was not performed in the remaining patient. The $B$ cepacia isolates from three of the 23 children were sensitive to aminoglycosides (tobramycin). Of these, two were chronically colonised (bacteriocin types S22/ $\mathrm{PO}$ and SO/PO) and one had only a single positive culture (bacteriocin type not available).

$B$ cepacia was sensitive to aztreonam in 22 of the 23 patients and, of these, 19 also showed sensitivity to azlocillin and two to ceftazidime.

In June 1992, following the increase in $B$ cepacia, segregation measures were introduced. Over the next few months a decline in the number of newly colonised children occurred (figure). One further case occurred in November 1992 after a holiday in Florida for children with cystic fibrosis, both with and without $B$ cepacia. Thereafter the downward trend continued, with only two new cases in the next 12 months, and the rate of $B$ cepacia acquisition has remained very low.

Eighteen (78\%) of the 23 who became colonised with $B$ cepacia were inpatients at a time that overlapped with admission of at least one other child with the organism (figure). The periods of overlap varied between one and 14 days. The time interval between possible exposure and first isolation of $B$ cepacia in sputum varied from 61 to 123 days.

During the same period 24 other children with cystic fibrosis were inpatients at the same time as a child with $B$ cepacia, but they did not subsequently become colonised with the organism. Again the period of overlap was 1-14 days. However, the children who did not become colonised were significantly younger $(5 \cdot 8$ years $v 10.4$ years; $\mathrm{p}<0.005)$. Seven were $P$ aeruginosa negative and therefore received their chest physiotherapy separately from the $P$ aeruginosa (and $B$ cepacia) group.

\section{BACTERIOCIN TYPES}

Bacteriocin types were available for 21 of the 23 B cepacia organisms: one child (subject 2) had only one positive sputum sample and another child (subject 22) was transferred to another unit around the time of colonisation (figure). All children had bacteriocin type S22/ PO except subject 4 (SO/PO), and subjects 9, 10, and 12 (all S13/PO). None of these bacteriocin types has been associated with fulminant illness due to $B$ cepacia. ${ }^{7}$

\section{GROUP COMPARATIVE DATA}

Sex distribution

While there were more girls in each group, there was no significant difference in sex distribution $\left(\chi^{2}=0 \cdot 14, \mathrm{df}=1, \mathrm{p}=\mathrm{NS} ;\right.$ table $)$.

\section{Age distribution}

The $B$ cepacia group was significantly older $\left(10.4\right.$ v 7.24 years; $\chi^{2}=8.5, \mathrm{df}=2, \mathrm{p}<0.05$; table). Because of the small numbers the patients were divided into three age groups (0-5, 6-10, and $11-14$ years); $36 \%$ of the children colonised with $P$ aeruginosa were in the youngest age group compared with only $18 \%$ of the $B$ cepacia group.

\section{Nutrition}

While there was no significant difference between groups in terms of the height distribution based on centiles $\left(\chi^{2}=2 \cdot 1, \mathrm{df}=5 ; \mathrm{p}=\mathrm{NS}\right.$ combining neighbouring categories as necessary for a valid test; table), there were significant differences in the weight distribution $\left(\chi^{2}=9 \cdot 6 ; \mathrm{df}=\right.$ 3 ; $p<0 \cdot 05$, again combining categories as necessary; table). In particular, $61 \%$ of the $B$ cepacia group had weights on or below the third centile compared with only $21 \%$ of the $P$ aeruginosa group. In the period following colonisation there was no significant change between the two groups for height or weight $\left(\chi^{2}=2 \cdot 5, \mathrm{df}=\right.$ 2 , and $0.90, \mathrm{df}=2$ respectively, $\mathrm{p}=\mathrm{NS}$ ). Thus, although more were poorly nourished at colonisation, the linear growth and nutrition of the $B$ cepacia group did not deteriorate disproportionately in the medium term.

\section{Pulmonary function}

The table shows the mean results for $\mathrm{FEV}_{1}$, PEFR, and the RV/TLC ratio at their baseline assessments. Some children were too young to undergo pulmonary function testing and, accordingly, the numbers in each group differ. For each variable there was no significant difference between the two groups (95\% confidence interval (CI) for the difference in the means $(-27 \cdot 1$ to $1 \cdot 8)$; $(-18 \cdot 3$ to $8 \cdot 1)$; and $(-22$ to 71$), p=N S)$. Between groups the mean changes in PEFR and RV/TLC over the study period did not differ. However, the average deterioration in $\mathrm{FEV}_{1}$ for the $B$ cepacia group was significantly greater than that of the $P$ aeruginosa group $(\mathrm{p}<0 \cdot 05)$. Somewhat surprisingly, the mean $\mathrm{FEV}_{1}$ for the $P$ aeruginosa group had improved 12 months after the baseline result, but not significantly. 
An analysis of covariance demonstrated that for both PEFR and RV/TLC the child's initial pulmonary function influenced the change in pulmonary function; for PEFR in both groups those with better initial values fell more, while for RV/TLC both groups declined in a similar direction but those with higher (worse) RV/ TLC values fell more. There was no evidence of a group effect on the change in either measurement. For the $B$ cepacia group this was also true of $\mathrm{FEV}_{1}$ in that those with higher initial values deteriorated more on average. However, for the $P$ aeruginosa group the initial $\mathrm{FEV}_{1}$ had no effect on the average change in $\mathrm{FEV}_{1}$ throughout the study period if one outlier, whose result distorts the analysis, is removed. The combination of $B$ cepacia and $P$ aeruginosa was therefore associated with a faster deterioration in lung function than infection with $P$ aeruginosa alone, and this was most evident in children with better initial lung function. The linear modelling was extended to investigate possible age effects and age group interactions but no significant effects were found.

\section{Swachman scores}

The median baseline Swachman scores ${ }^{13}$ for the $B$ cepacia group was significantly lower ( $95 \% \mathrm{CI}-5$ to $-25, \mathrm{p}<0.05$; table). The median scores for children in both groups who had scores available showed no difference between groups in the median reduction in scores over the period of the study $(95 \% \mathrm{CI}-5$ to $-15, \mathrm{p}=\mathrm{NS}$ ).

\section{Mortality}

During the study period five children (two boys and three girls) in the $B$ cepacia group died between five and 15 months after colonisation.

Baseline data of children at acquisition of $B$ cepacia colonisation compared with those colonised with P aeruginosa alone

\begin{tabular}{|c|c|c|}
\hline & $\begin{array}{c}P \text { aeruginosa } \\
B \text { cepacia }\end{array}$ & $\begin{array}{c}P \text { aeruginosa } \\
\text { alone }\end{array}$ \\
\hline $\mathrm{n}$ & 23 & 33 \\
\hline $\begin{array}{l}\text { Sex } \\
\text { Boys } \\
\text { Girls }\end{array}$ & $\begin{array}{l}10 \\
13\end{array}$ & $\begin{array}{l}16 \\
17\end{array}$ \\
\hline $\begin{array}{l}\text { Age groups } \\
0-5 \text { years } \\
6-10 \text { years } \\
11-14 \text { years }\end{array}$ & $\begin{array}{r}4 \\
10 \\
9\end{array}$ & $\begin{array}{r}18 \\
10 \\
5\end{array}$ \\
\hline $\begin{array}{l}\text { Height centile } \\
\quad 0-3 \\
>3-10 \\
>10-25 \\
>25-50 \\
>50-75 \\
>75-90 \\
>90-100\end{array}$ & $\begin{array}{l}5 \\
6 \\
3 \\
3 \\
2 \\
3 \\
1\end{array}$ & $\begin{array}{l}4 \\
7 \\
5 \\
6 \\
6 \\
2 \\
3\end{array}$ \\
\hline $\begin{array}{l}\text { Weight centile } \\
0-3 \\
>3-10 \\
>10-25 \\
>25-50 \\
>50-75 \\
>75-90 \\
>90-100\end{array}$ & $\begin{array}{r}14 \\
3 \\
1 \\
3 \\
0 \\
0 \\
2\end{array}$ & $\begin{array}{r}7 \\
10 \\
1 \\
7 \\
6 \\
1 \\
1\end{array}$ \\
\hline Swachman scores (median, range) & $65(30-90)^{*}$ & $85(50-95)^{* *}$ \\
\hline $\begin{array}{l}\text { Lung function (\% predicted) } \\
\text { FEV }_{1} \\
\text { PEF } \\
\text { RV/TLC }\end{array}$ & $\begin{array}{c}(\mathrm{n}=18) \\
71 \cdot 4 \\
83 \cdot 1 \\
279 \cdot 1\end{array}$ & $\begin{array}{c}(\mathrm{n}=20) \\
84 \cdot 0 \\
88 \cdot 2 \\
254 \cdot 3\end{array}$ \\
\hline
\end{tabular}

* 14 scores available; ** 19 scores available.

$\mathrm{FEV}_{1}=$ forced expiratory volume in one second; $\mathrm{PEF}=$ peak expiratory flow; $\mathrm{RV}=$ residual volume; TLC $=$ total lung capacity.
Since the start of the study only one child not colonised with $B$ cepacia has died due to a brainstem glioblastoma. The five children colonised with $B$ cepacia who died all suffered a steady clinical deterioration. Prior to colonisation with $B$ cepacia they were not in a particularly poor condition with respect to either nutrition or pulmonary function.

A further four with $B$ cepacia have died since the end of the study.

\section{Discussion}

This report describes a substantial hospital outbreak of $B$ cepacia infection in a children's cystic fibrosis centre, and the impact of colonisation on the subsequent outcome.

The data provide further evidence that patient to patient transmission of $B$ cepacia occurs. Firstly, the incidence of $B$ cepacia infection rose rapidly with most of the children who became colonised being in contact during their hospital stay with at least one other child colonised with the organism. The potential duration of exposure to $B$ cepacia was not long, between one and 14 days, and is similar to the six days previously reported between two children attending a summer camp. ${ }^{10}$ Secondly, more than $74 \%$ of children became colonised with a single bacteriocin type, S22/PO. Two children were colonised with this type at the start of the outbreak and may have been the original source. Patient 1 had been colonised with bacteriocin type S22/PO for two years before the outbreak. Although this child was not admitted to the ward for four months before the outbreak, there had been social contact with other children with cystic fibrosis. The same type was isolated from patient 3 who was first found to be colonised after a brief attendance at another cystic fibrosis centre. The isolation of three bacteriocin types suggests that the outbreak did not arise solely from direct patient to patient cross infection. The index cases of the other two bacteriocin types may represent acquisition from the environment. Our data suggest that this is a less important source than patient to patient spread. Other centres have also reported mutiple types, usually with one predominating. ${ }^{714}$

The nature of the contact necessary for transmission of $B$ cepacia is not clear - for example, by droplet spread or via contaminated fomites or by aerosol spread. A number of reports have linked attendance at cystic fibrosis camps to acquisition of $B$ cepacia ${ }^{15-17}$ when there appears to be an opportunity for prolonged exposure of non-colonised children to colonised ones, especially through communal activities such as physiotherapy which might promote spread either via aerosols or contaminated fomites. ${ }^{7}$ None of the children had recently attended cystic fibrosis camps but, at the time of our outbreak, all the children colonised with Pseudomonas species in hospital were having communal physiotherapy in an enclosed space. In stark contrast, the children with cystic fibrosis who were not colonised with $P$ aeruginosa at the same time and who received their physiotherapy separately did not become colonised 
with $B$ cepacia. It is of interest that Humphreys et $a l^{18}$ noted that $B$ cepacia could be recovered from room air during occupation by five or six patients with cystic fibrosis colonised with $B$ cepacia. The number of bacteria isolated was greater when the patients were coughing. The isolation of $B$ cepacia from the air of rooms occupied by colonised patients suggests that dissemination can occur by aerosol spread. In using communal physiotherapy in an enclosed space we may inadvertently have created an environment conducive to the spread of $B \mathrm{ce}$ pacia. The children who became colonised with $B$ cepacia were significantly older and it is possible that some spread arose from social contact, ${ }^{7}$ more likely in older children, especially in a hospital setting. Interestingly, three children colonised with $B$ cepacia had siblings with cystic fibrosis, but only one sibling became colonised, in contrast to previous studies where pairs of siblings generally showed mutual colonisation. ${ }^{49}$

The other possibility that the infection arose and spread from a common environmental source is unlikely. Firstly, at the time of the outbreak children were not sharing respiratory equipment so that spread via contaminated equipment is improbable. Also, surveillance cultures of respiratory function equipment have always failed to recover $B$ cepacia. Secondly, types identified on subsequent environmental screening of sites such as sinks were of different bacteriocin types than those isolated from colonised children. Finally, simple cross infection measures involving segregation of children colonised with $B$ cepacia, with no additional environmental measures, effectively interrupted the progress of the outbreak.

Not all of the children in the $P$ aeruginosa group exposed to $B$ cepacia became colonised. Those who did were older, less well nourished, and had lower Swachman scores, but did not have worse lung function. During the study there was no evidence of deterioration in nutrition, linear growth, or clinical score in either group. To date it has not been clear whether $B$ cepacia colonisation is responsible for the deterioration in lung function in patients with cystic fibrosis or whether it is simply a marker of disease severity. At the time of colonisation the lung function between the two groups did not differ significantly. While there was no evidence of a decline in lung function within each group, the group colonised with both $B$ cepacia and $P$ aeruginosa showed a significant decline in $\mathrm{FEV}_{1}$ compared with the group colonised with $P$ aeruginosa only. Further analysis of the $\mathrm{FEV}_{1}$ results in the $B$ cepacia group showed that those with the highest $\mathrm{FEV}_{1}$ values (that is, $>50 \%$ predicted) deteriorated the most. Colonisation with $B$ cepacia was also associated with a significant mortality from respiratory failure. ${ }^{7}$ Thus, the dominant impact of $B$ cepacia in children with cystic fibrosis is on respiratory function, and may be greater in those with better levels of respiratory function. This contrasts with the adults and adolescents described by Taylor $e t a l^{19}$ in whom those with normal or mild lung disease at the outset of infection remained clinically stable, whereas few of those with severe disease remained stable.

In conclusion, cross infection with $B$ cepacia arising from person-to-person spread is an important problem in children with cystic fibrosis, and has a major impact on the respiratory system which is reflected in a faster decline in $\mathrm{FEV}_{1}$ and a higher mortality from respiratory failure. Simple measures to limit cross infection dramatically reduce the incidence of new infections, emphasising that measures to limit the spread of this organism should be introduced in all paediatric cystic fibrosis units.

1 Isles A, Maclusky I, Coney M, Gold R, Prober C, Fleming $\mathrm{P}$, et al. Pseudomonas cepacia infection in cystic fibrosis: an $\mathrm{P}$, et al. Pseudomonas cepacia infection in cystic fib

2 Thomassen MJ, Demko CA, Klinger JD, Stern RC. Pseudomonas cepacia colonisation among patients with cystic fibrosis: a new opportunist. Am Rev Respir Dis 1985;131 791-6.

3 Tablan OC, Martone WJ, Doershuk CF, Stern RC, Thomassen $\mathrm{MJ}$, Klinger JD, et al. Colonisation of the respiratory tract with Pseudomonas cepacia in cystic fibrosis. Risk factors and outcome. Chest 1987;191:527-32.

4 Tablan OC, Chorba TL, Schidlow DV, White JW, Hardy KA, Gilligan PH, et al. Pseudomonas cepacia colonisation in patients with cystic fibrosis: risk factors and clinical in patients with cystic fibrosis: risk

5 Simmonds EJ, Conway SP, Ghoniem ATM, Ross H, Littlewood JM. Pseudomonas cepacia: a new pathogen in patients with cystic fibrosis referred to a large centre in the United Kingdom. Arch Dis Child 1990;15:874-7.

6 Taylor RF, Dalla Costa L, Kaufmann NE, Pitt TL, Hodson ME. Pseudomonas cepacia pulmonary infection in adults with cystic fibrosis: is nosocomial acquisition occurring? f Hosp Infect 1992;21:199-204.

7 Govan JR, Brown PH, Maddison J, Doherty CJ, Nelson JW, Dodd M, et al. Evidence for transmission of Pseudomonas cepacia by social contact in cystic fibrosis. Lancet 1993; 342:15-9.

8 Nelson JW, Doherty CJ, Brown PH, Greening AP, Kaufman ME, Govan JRW. Pseudomonas cepacia in inpatients with cystic fibrosis. Lancet 1991;338:1525.

9 Thomasen MJ, Demko CA, Doershuk CF, Stern RC Klinger JD. Pseudomonas cepacia: decrease in colonisation in patients with cystic fibrosis. Am Rev Respir Dis 1986; 134:669-71.

10 Li Puma JJ, Dasen SE, Neilson DW, Stern RC, Stull TL. Person-to-person transmission of Pseudomonas cepacia between patients with cystic fibrosis. Lancet 1990;336:10946 .

11 Hardy KA, McGowan KL, Fisher MC, Schidlow DV. Pseudomonas cepacia in the hospital setting: lack of transmission between cystic fibrosis patients. $\mathcal{F}$ Pediatr 1986; 109:51-4.

12 Govan JRW, Harris G. Typing of Pseudomonas cepacia by bacteriocin susceptibility and production. $\mathcal{F}$ Clin Microbiol 1985;22:490-4.

13 Swachman H, Kulczycki LL. Long term study of one hundred and five patients with cystic fibrosis. Am $\mathcal{F} D$ is Child 1958;96:6-15.

14 Fisher MC, LiPuma JJ, Dasen SE, Caputo GC, Mortensen JE, McGowan KL, et al. Sources of Pseudomonas cepacia: ribotyping of isolates from patients and from the en vironment. $\mathcal{F}$ Pediatr 1993;123:745-7.

15 Anonymous. Pseudomonas cepacia at summer camps for persons with cystic fibrosis. MMWR 1993;42:456-9.

16 John M, Ecclestone E, Hunter E, Couroux P, Hussain Z Epidemiology of Pseudomonas cepacia: colonisation among patients with cystic fibrosis. Pediatr Pulmonol 1994;18: 108-13.

17 Kaplan TA, McKey Jr RM, Toraya N, Moccia G. Impact of summer camp. Clin Pediatr 1992;31:161-7.

18 Humphreys H, Peckham D, Patel P, Knox A. Airborne dissemination of Burkholderia (Pseudomonas) cepacia from adult patients with cystic fibrosis. Thorax 1994;49:1157-9.

19 Taylor RFH, Gaya H, Hodson ME. Pseudomonas cepacia: pulmonary infection in patients with cystic fibrosis. Respir Med 1993;87:187-92. 